\title{
Changes in Proline Levels during Seed Development of Orthodox and Recalcitrant Seeds of Genus Acer in a Climate Change Scenario
}

\author{
Joanna Kijowska-Oberc ${ }^{1, *(\mathbb{D})}$, Aleksandra M. Staszak ${ }^{2}$ (), Mikołaj K. Wawrzyniak ${ }^{1}$ (D) \\ and Ewelina Ratajczak ${ }^{1}$ (D) \\ 1 Institute of Dendrology, Polish Academy of Sciences, Parkowa 5, 62-035 Kornik, Poland; \\ mikwaw@man.poznan.pl (M.K.W.); eratajcz@man.poznan.pl (E.R.) \\ 2 Laboratory of Plant Physiology, Department of Plant Biology and Ecology, Faculty of Biology, \\ University of Bialystok, Ciolkowskiego 1J, 15-245 Bialystok, Poland; a.staszak@uwb.edu.pl \\ * Correspondence: joberc@man.poznan.pl
}

Received: 23 October 2020; Accepted: 16 December 2020; Published: 18 December 2020 updates

\begin{abstract}
In the present study, we examined the utility of proline usage as a biochemical indicator of metabolic changes caused by climate change (mean temperature and precipitation) during seed development of two Acer species differing in desiccation tolerance: Norway maple (Acer platanoides L.-desiccation tolerant-orthodox) and sycamore (Acer pseudoplatanus L.—desiccation sensitive-recalcitrant). In plants, proline is an element of the antioxidant system, which has a role in response to water loss and high temperatures. Our study considered whether proline could be treated as an indicator of tree seed viability, crucial for genetic resources conservation. Proline content was measured biweekly in developing seeds (between 11 and 23 weeks after flowering) collected in consecutive years (2017, 2018, and 2019). We showed that proline concentrations in recalcitrant seeds were positively correlated with mean two-week temperature. In contrast, in orthodox seeds no such relationship was found. Proline content proved to be sensitive to thermal-moisture conditions changes, which makes it a promising biochemical marker of seed desiccation tolerance in different climatic conditions.
\end{abstract}

Keywords: environmental conditions; tree seeds; proline; drought; seed desiccation; oxidative changes

\section{Introduction}

The process of seed development occurs in several different stages, such as the development of seed tissues, storage reserve accumulation, and maturation drying [1]. The seed is a very important phase in the plant life cycle, and seeds, similar to other plant organs, deteriorate under unfavorable conditions, such as water deficits, excessive heat or cold, and salinity [2,3]. The regulatory redox signaling network in plant cells detects every metabolic imbalance and modulates a response, which results in quick adaptation to the rapidly changing environmental conditions and production of high-quality seeds [4]. Previous experiments indicate that redox-state regulation takes place during seed development and can be closely linked with maintenance of seed viability during long-term storage [5-8].

Desiccation is required at the maturation stage of seed development (Figure 1), inducing a dormancy state in which seeds enter a state of quiescence until a favorable environment is found and germination is induced $[9,10]$. Seeds differ in desiccation tolerance, and these differences occur within families and genera, e.g., maple (Acer). The acquisition of desiccation tolerance of Norway maple (A. platanoides L.) seeds is an adaptive strategy that facilitates survival in unfavorable environmental conditions, which is a characteristic of the orthodox seed category. The water content of recalcitrant 
sycamore (A. pseudoplatanus L.) seeds remains high throughout their development until germination, and these seeds cannot be stored for long periods of time [11,12].

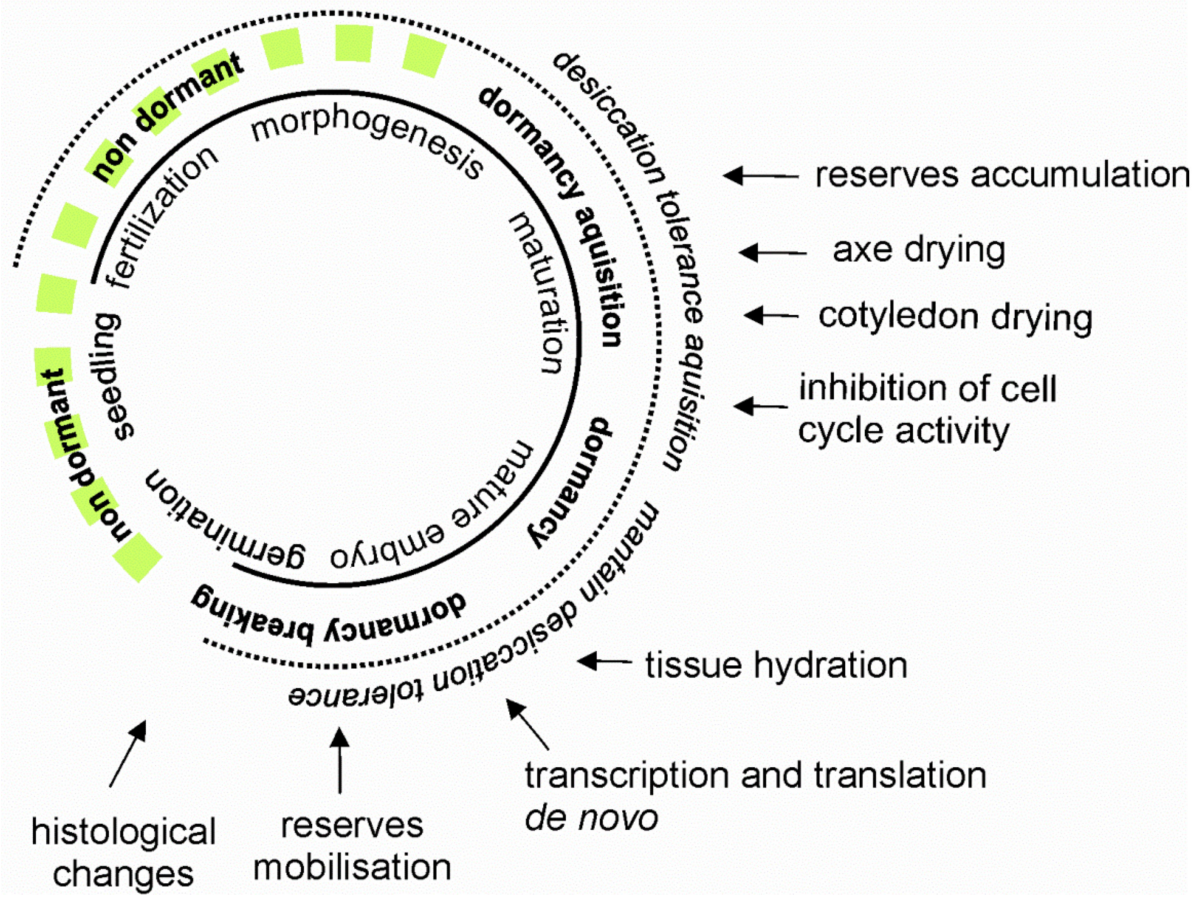

Figure 1. Subsequent phases that occurs in seeds. Inside the ring, developmental processes from fertilization through morphogenesis, maturation to germination are shown. Outside the ring, physiological aspects accompanying the seed development are shown in relation to desiccation tolerance (italic) and dormancy (bold). Arrows indicate each moment of seed development as it occurs, e.g., accumulation of reserves, axe and cotyledon drying, transcription de novo, and reserves mobilization.

Changing environmental conditions may disturb redox homeostasis via the induction of an excessive accumulation and decreased elimination of reactive oxygen species (ROS), e.g., $\mathrm{OH}^{-}$, $\mathrm{H}_{2} \mathrm{O}_{2}$, and $\mathrm{O}_{2}^{\bullet-}[4,5]$. ROS molecules cause damage via lipid peroxidation, enzyme inactivation, and disruption of protein, carbohydrate, and DNA structures, which inhibit germination and further plant development [13]. Plant cells have developed special mechanisms to prevent changes in ROS levels. One of these mechanisms involves the accumulation of osmolytes, such as proline, which protect cells against stress-induced damage via osmotic adjustments [14]. Proline accumulation is an intracellular signal that is connected with water loss prevention mechanisms and other adaptive responses in higher plants [2]. This amino acid accumulates during conditions of drought, high salinity, heavy metals, and biotic stresses [15]. Proline reduces oxidative damage to the lipid membranes [16] and stabilizes these structures, which enables seed germination [17]. Proline also plays an important role in ROS removal $[15,18]$ by acting as a chaperone to improve protein stability and integrity, including antioxidant enzymes [19]. Protein activity is subsequently increased, which facilitates the capacity to withstand environmental stresses [20]. The metabolism of proline is associated with electron transfer between mitochondria and chloroplasts, and therefore, proline influences the redox state of these organelles [21]. Furthermore, the evident differences in protein thiol levels between the seed tissues of Norway maple and sycamore reflect the distinct metabolic states of these two genetically related species [6,22]. Protein thiol levels in Norway maple embryonic axes decrease after desiccation tolerance acquisition, which suggests that oxidation of these proteins is related to metabolic quiescence of the seed [23]. This sort of relationship was not observed in sycamore desiccation-sensitive seeds, whose embryos remain metabolically active during drying, as is reflected by protein thiol levels during the development of the embryonic axes of sycamore seeds [22,24,25]. Thiol-disulfide transitions play an 
important role in cell signaling by control of catalytic activities, regulatory switches, and protective mechanisms [26]. However, redox processes may participate in metabolic regulation in maturing seeds [27]. Oxidation of protein thiol to disulfides is connected with desiccation tolerance acquisition of Norway maple seeds, and in the case of sycamore seeds metabolic processes leads to energy substrate exhaustion [22].

The loss of seed viability in trees due to changing environmental conditions and meteorological phenomena, such as drought and high temperatures, is not completely understood as a process because of its complex character, which consists of molecular, physiological [28], and phenological changes, such as mast-seeding desynchronization [29] or bloom timing [30]. Climate change affects a range of species and the reproduction of trees, and it may have long-term consequences, such as reducing species dispersion and the acquisition of new habitats [29]. Many studies have confirmed the impact of climate change on tree species ranges or phenological events [31]. Therefore, there is an indisputable need to protect forest reproductive material via collection and storage for species conservation and to maintain the continuity of renewals in commercial forests [29,32].

The study of desiccation tolerance during seed development is fundamental to determine optimal seed storage conditions and prevent quality loss [1]. However, some issues of forest tree stress biology, such as how climate change affects the basic molecular mechanisms of tree seed vitality during development, are not known. Although the redox-state regulation system in plant tissues is quite well characterized [13,33,34], there are no thorough investigations on how climate change affects the biochemical modulation of different processes such desiccation tolerance acquisition during seed development. Therefore, the development of a fast-acting, universal, and unambiguous marker of seed desiccation tolerance in trees would be useful to assess the quality of seeds collected from different climatic conditions, and to assure successful storage [35].

The present study explored the changes of proline levels in embryonic axes and cotyledons of an orthodox (Acer platanoides L.) and a recalcitrant (Acer pseudoplatanus L.) species in response to increased temperatures and decreased precipitation during seed development. Our results confirm differences in desiccation tolerance occurring within the same tree genus, which is important for the economic use of their seeds. The development of a fast and unambiguous marker of desiccation tolerance in seeds will allow the identification of high-quality forest gene resources before storage and, by that means, to preserve them in the face of a rapidly changing climate.

\section{Materials and Methods}

\subsection{Plant Materials Collection}

The seeds were collected from single trees of Norway maple and sycamore growing in the Kórnik Arboretum (Western Poland). Seeds were collected at 2-week intervals beginning 11 weeks after flowering (WAF) for sycamore and 14 WAF for Norway maple in the years 2017, 2018, and 2019 (Table 1). We indicated an approximate measure of WAF based on peak flowering dates, observed on our source trees. After harvest, the seeds were transferred immediately to the laboratory in sealed plastic bags. The determination of seed water content (WC, fresh weight basis) and analysis of proline levels were performed on the day of seed collection.

Table 1. Dates of flowering of Norway maple and sycamore maple in this study.

\begin{tabular}{ccc}
\hline \multirow{2}{*}{ Year } & \multicolumn{2}{c}{ Flowering Date } \\
\cline { 2 - 3 } & Norway Maple & Sycamore Maple \\
\hline $\mathbf{2 0 1 7}$ & 24 April & 1 May \\
$\mathbf{2 0 1 8}$ & 15 April & 22 April \\
$\mathbf{2 0 1 9}$ & 5 April & 12 April \\
\hline
\end{tabular}


According to previous findings that the analysis of whole seeds at the biochemical level gives complete and unambiguous results, during these experiments we used seed embryonic axes and cotyledons separately. Axes showed greater sorption properties than cotyledons and are more prone to different oxidative changes [7].

\subsection{Proline Extraction and Determination}

Proline extraction to determine the concentrations was made according to a modified method Petronia Carillo and Yves Gibon [36]. Proline was extracted using a cold extraction procedure by mixing 20-50 mg fresh weight of embryonic axes (pools of 20 individuals in every sample) or cotyledon (pools of 5 individuals in every sample) aliquots separately with 0.4-1 mL of ethanol: water (40:60 v/v). The resulting mixture was left overnight a $4{ }^{\circ} \mathrm{C}$ and then centrifuged at $14,000 \times g(5 \mathrm{~min})$.

Proline solutions ranging from 0.04 to $1 \mathrm{mM}$ diluted in the same medium as the one used for extraction. The reaction mix $(1 \%(w / v)$ ninhydrin in $60 \%(v / v)$ acetic acid and $20 \%(v / v)$ ethanol) was added to the sample aliquots and to the standards and measurements were performed at $520 \mathrm{~nm}$. Proline concentration was determined based on the standard curve.

Data are presented as the means of three samples from each collection date, \pm SD (standard deviation).

\subsection{Water Content Determination}

Fresh weights of embryonic axes (pools of 10 individuals in every sample) and cotyledons (pools of 5 individuals in every sample) were measured separately. Subsequently, samples were desiccated for $24 \mathrm{~h}$ at $100{ }^{\circ} \mathrm{C}$ and after that, the dry weight was measured. To determine seed WC, seed dry weight was subtracted from seed fresh weight. Data are presented as means of the three samples from each collection date \pm SD.

\subsection{Meteorology Data}

Temperature and precipitation were obtained from the Institute of Meteorology and Water Management, Poznan Department, Kórnik Station (52 $14^{\prime} 40.9^{\prime \prime}$ N 1706 $03.3^{\prime \prime}$ E).

\subsection{Statistical Analysis}

The effects of stage of maturity (WAF) and embryo parts (embryonic axis and cotyledon) on proline and water content in each experimental year were evaluated using a linear model. A one-way ANOVA was used to tests significant differences between mean values. Pairwise comparisons between treatments we performed using Duncan's multiple range test at $p \leq 0.05$. Data were tested for ANOVA assumption violation with Shapiro-Wilk and Levene's tests. Percentage data (water content) were transformed using the Bliss equation.

Non-parametric Spearman correlations were calculated for proline content, water content, and climate parameters as assumption of data normality was violated. For correlation, proline content and the WAF non-linear estimator were calculated. Data were analyzed using R software [37]. For correlation calculations and visualization, the correlation package was used [38].

\section{Results and Discussion}

We confirmed that the orthodox seeds of Norway maple and recalcitrant seeds of sycamore responded to environmental conditions, such as biweekly mean temperature and biweekly mean precipitation (Figures 2-5). The water content of embryonic axes in Norway maple seeds decreased in 2017 , and the proline content gradually increased, reaching a maximum at 18 WAF, when the temperature reached its maximum, then significantly decreased at 22 WAF when precipitation simultaneously decreased (Figures 2,3A and 4A). A statistically significant decrease in proline content occurred at 20 WAF in 2018 (Figure 3B). In 2019, the proline content of Norway maple embryonic axes decreased significantly at 22 WAF (Figure 3C) when the water content reached a minimal level (Figure 4). 
Similarly to the Norway maple, differences in proline content in seed embryonic axes of sycamores were statistically significant for every year of observations (Figure $3 \mathrm{~A}^{\prime}-\mathrm{C}^{\prime}$ ). However, a significant correlation between proline levels and thermal-moisture conditions was found in recalcitrant seeds of sycamore only (Figure 5). Proline content in sycamore correlated moderately positively with biweekly mean temperature in both embryonic axes (0.62) and cotyledons (0.34), but negatively correlated with biweekly mean precipitation in embryonic axes (-0.34) (Figure 5C).

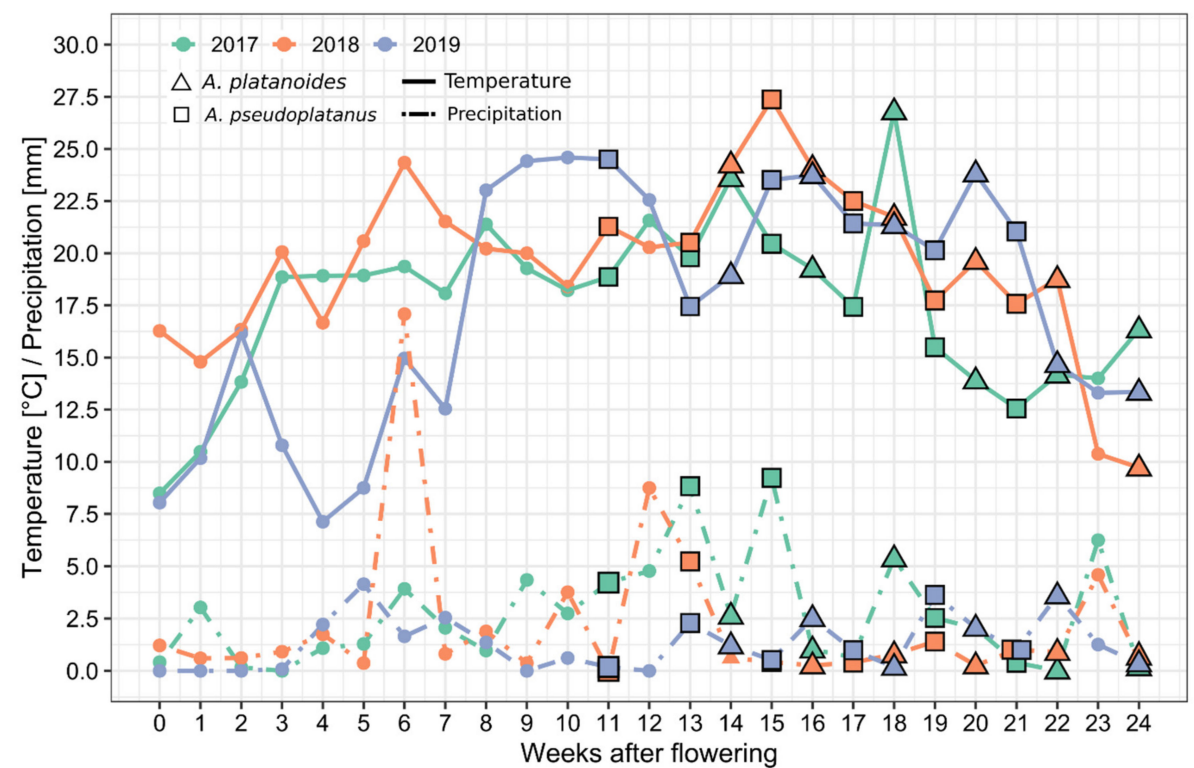

Figure 2. Weekly mean temperature (solid line) and mean precipitation (dashed line) during flowering and seed maturation in each experimental year. Seed samples for proline analyses were collected in weeks marked with symbols $(\square)$ for Sycamore and $(\triangle)$ for Norway maple.

The proline content in cotyledons for both species increased gradually during development then decreased primarily in the last week or last two weeks of observations (Figure S1). Statistically significant decreases occurred in Norway maples in 2017 at 22 WAF (Figure 3A) and 2018 at 24 WAF (Figure 3B) and in sycamore in 2017 at 19 WAF (Figure 3A'), 2018 at 21 WAF (Figure 3B') and 2019 at 19 WAF (Figure 3C'). The cotyledons of the examined species were more resistant to thermal-moisture conditions (Figure 5). We observed a significant positive correlation with mean temperature in sycamore but no significant negative correlation with mean precipitation (Figure 5D). Cotyledons of Norway maple showed no correlation in any tested parameter (Figure 5B). There was no significant correlation between seed moisture content and proline concentration in either tested species.

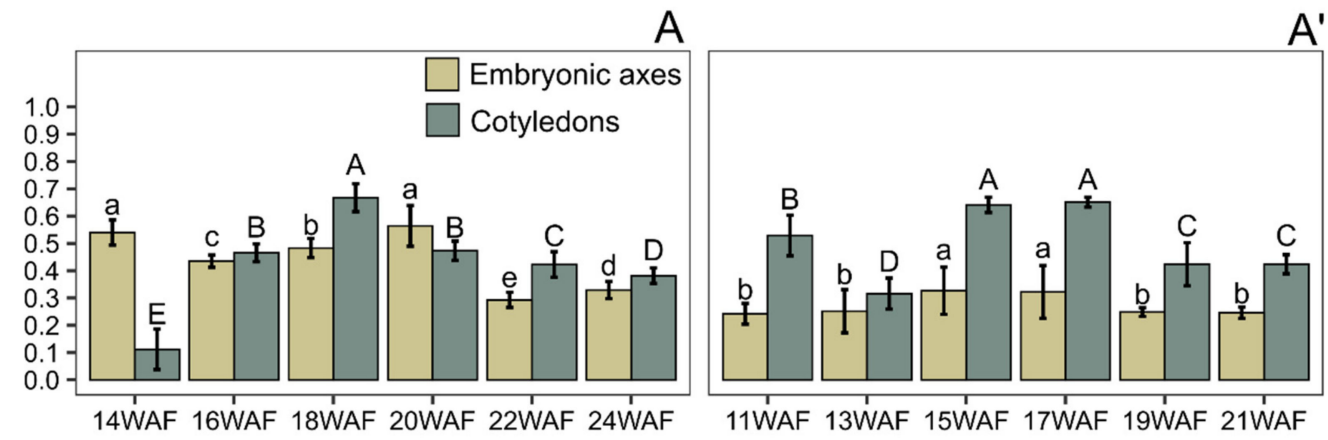

Figure 3. Cont. 


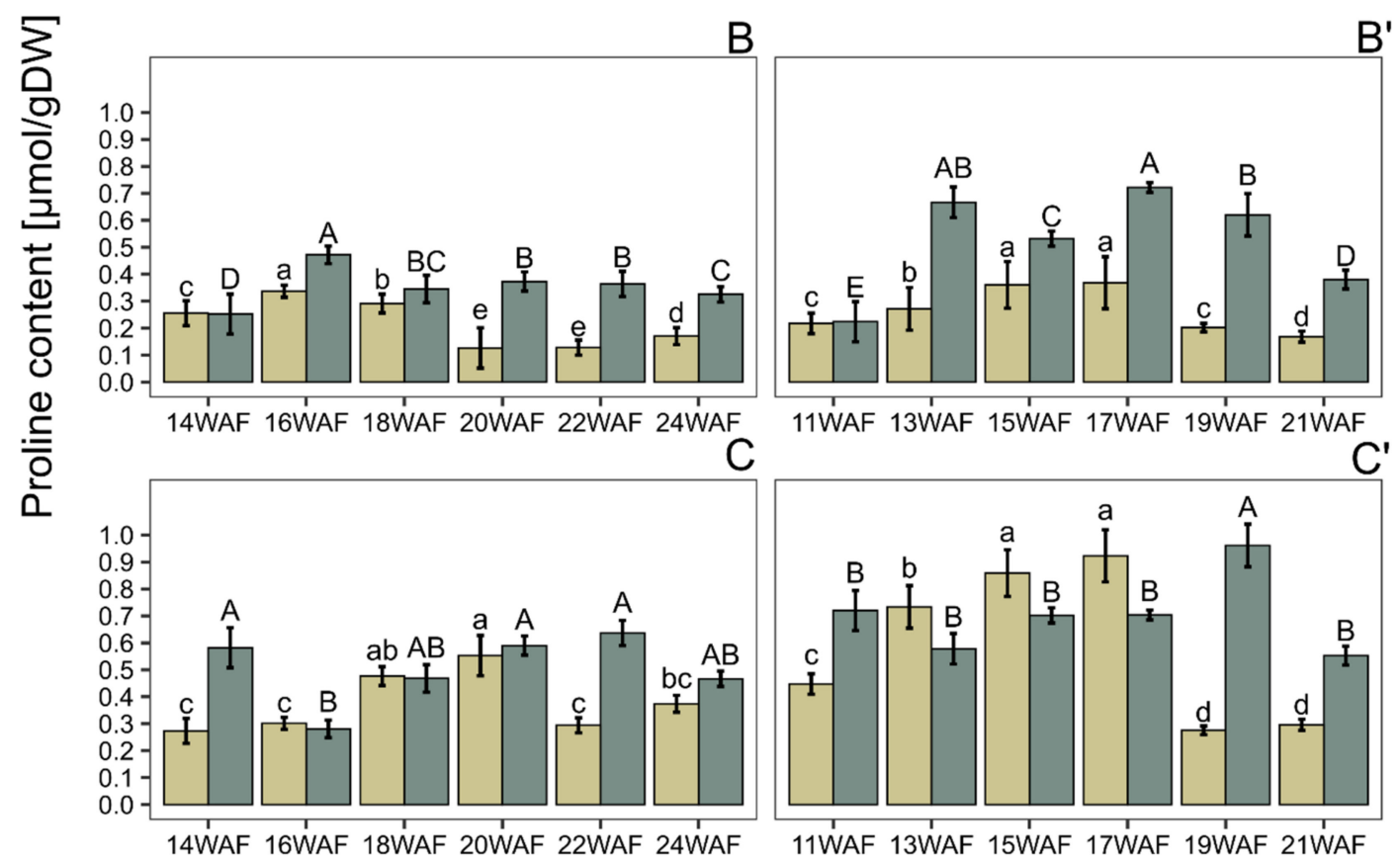

Figure 3. Proline content in subsequent weeks after flowering (WAF) in embryonic axes and cotyledons in Norway maple seeds collected in 2017 (A), 2018 (B), and (C) 2019, and sycamore seeds collected in $2017\left(\mathbf{A}^{\prime}\right), 2018\left(\mathbf{B}^{\prime}\right)$, and $2019\left(\mathbf{C}^{\prime}\right)$. Results represent the means of three samples \pm SD. Means not sharing the same letter (upper or lower case) are significantly different (Duncan test, $p<0.05$ ).
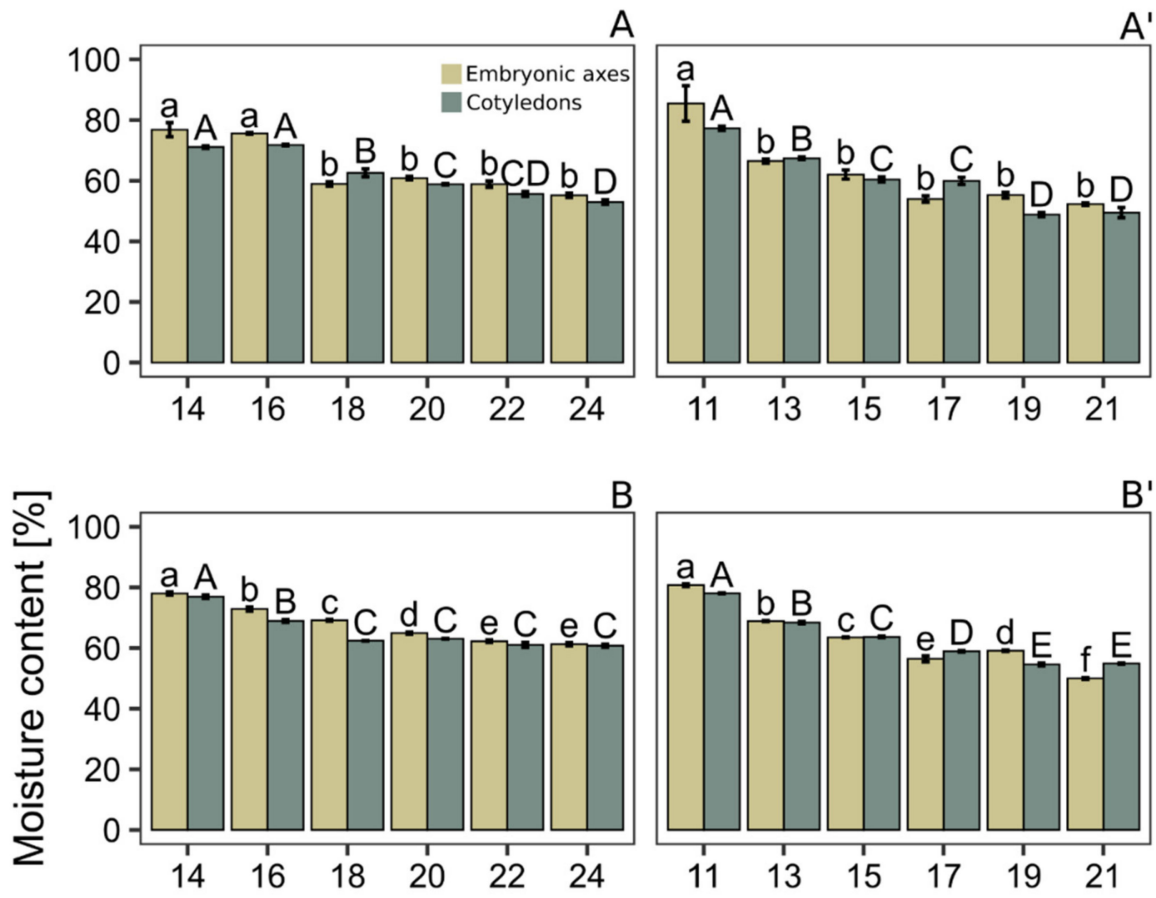

Figure 4. Cont. 


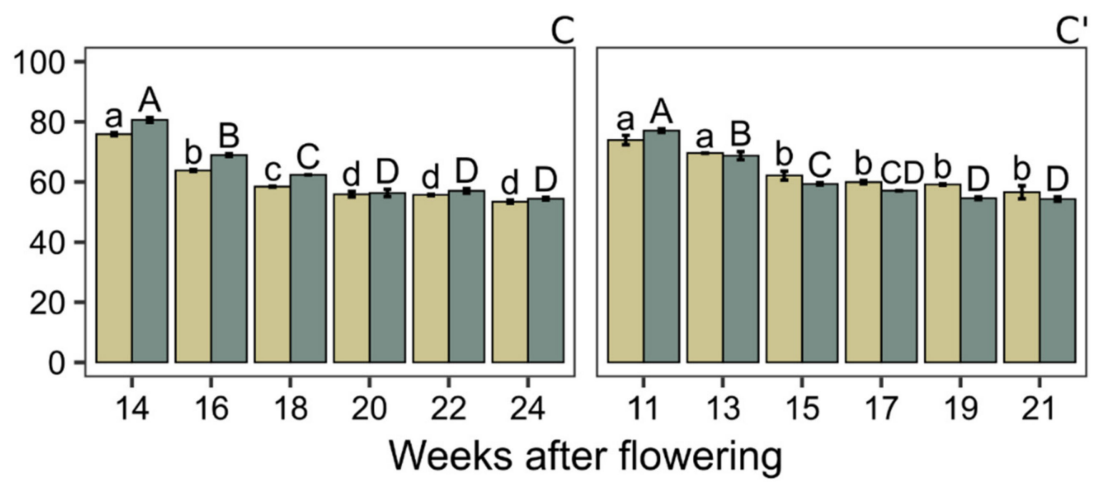

Figure 4. Water content in subsequent WAF in embryonic axes and cotyledons in Norway maple seeds collected in years 2017 (A), 2018 (B), and (C) 2019, and in sycamore seeds collected in 2017 (A'), $2018\left(\mathbf{B}^{\prime}\right)$, and $2019\left(\mathbf{C}^{\prime}\right)$. Results represent the means of tree samples \pm SD. Means not sharing the same letter (upper or lower case) are significantly different (Duncan test, $p<0.05$ ).

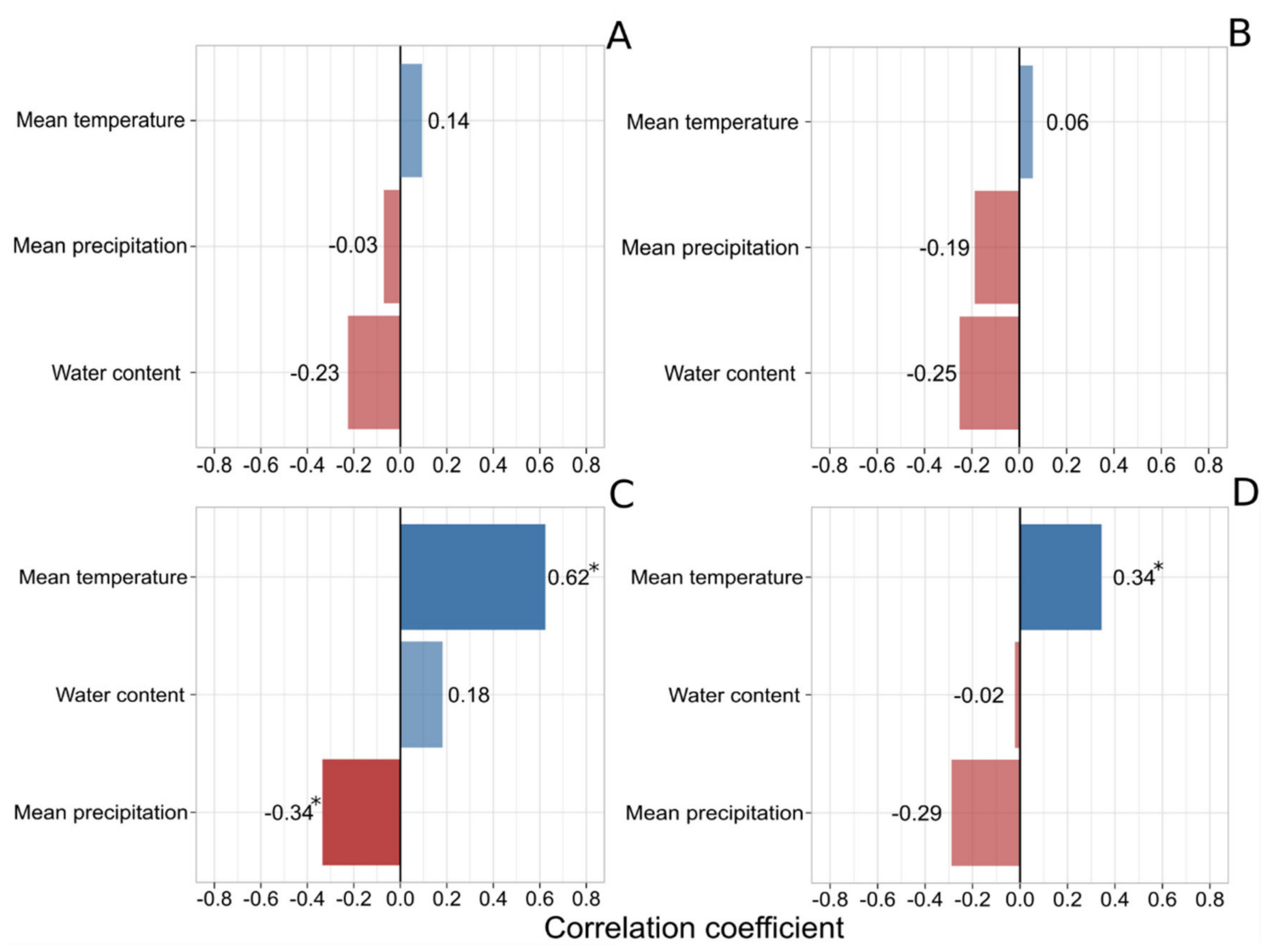

Figure 5. Correlations of proline content with tested parameters: biweekly mean temperature, water content, and biweekly mean precipitation for embryonic axes (A) and cotyledons (B) of Norway maple seeds, and embryonic axes (C) and cotyledons (D) of sycamore seeds. Columns marked "*" show significant correlation at $p$-value $\leq 0.05$. Data are the means of three samples, \pm SD.

The presented correlations indicate the main difference in seed desiccation tolerance between orthodox and recalcitrant seeds. Specifically, during development, orthodox seeds acquire the ability to withstand water loss and survive under extreme environmental conditions [34]. Before the water content decreases at approximately the 18th week after flowering (WAF), the orthodox seeds of Norway maple acquire water stress tolerance, which facilitates seed storage in a dry state under control conditions $[5,39,40]$. It is an effect of some intracellular modifications, such as the accumulation of lipids and starches, which improve cell mechanical resilience. The water content limit in orthodox seeds is 
$<7 \%$ (dry weight), but recalcitrant seeds can be desiccated from 0.20 to $0.3 \mathrm{~g} \mathrm{H}_{2} \mathrm{O} \mathrm{g}^{-1}$ dry weight [41]. Recalcitrant seeds remain sensitive to desiccation and low temperatures during development and after shedding. Constant increase in protein thiols during the development of sycamore embryonic axes indicates that recalcitrant seeds are not able to shut down their metabolism during drying, which may lead to substrate exhaustion [12,24]. Therefore, these seeds may lose viability during long-term storage [42]. In contrast, protein thiols decreased in desiccating Norway maple seeds immediately after desiccation tolerance acquisition [6]. We noticed increases in proline content in recalcitrant seeds of sycamore in response to higher temperatures and lower precipitation, which confirms that these trees mitigated these environmental stress conditions with higher proline content in their seeds. Proline levels in both species were the highest in 2019, when the precipitation during seed collection between 11 and 24 WAF was noticeably lower than the other two years (Figure 2). The years of 2017, 2018, and 2019 were warmer than the average of the 1979-2019 reference period, but only in 2019 was mean precipitation lower than the average of the reference period (Figure S2 and S3). The production of intracellular proline as a means to respond to the increasing ROS levels may be connected with mechanisms of water loss prevention in seeds deprived of the ability to survive under extreme environmental conditions [17]. To better understand the correlation between proline content and current climate conditions, a long-term experiment should be performed.

Proline is involved in the ascorbate-glutathione (ASC-GSH) cycle and participates in ROS protection $[43,44]$ by decreasing lipid peroxidation and $\mathrm{H}_{2} \mathrm{O}_{2}$ content and increasing the activities of antioxidative enzymes [45], e.g., ascorbate peroxidase (APX) [46]. Pukacka and Ratajczak [6] reported that the activity of APX and ASC was similar in seeds of Norway maple and sycamore species before desiccation, but products of $\mathrm{H}_{2} \mathrm{O}_{2}$ detoxification were effectively reduced to the initial form in orthodox seeds compared to recalcitrant seeds. These results suggest that orthodox seeds are prepared for water loss before the drying associated with maturation because relatively higher GSH and ACS contents reduce the intracellular redox environment, which promotes the removal of excess ROS [6,47]. Nowadays, the question is how do plants protect their seeds according to detection of changing weather conditions, if proline modulates the signal subscribed in seeds via desiccation tolerance?

Previous proteomic studies showed that proline aminopeptidase (PAP) may affect decreases in intracellular proline levels [48]. Staszak and Pawłowski [10] noted that PAP content gradually increased during Norway maple seed development and demonstrated an inactivation or biotransformation of proline by this enzyme. The maximum PAP content occurred at 22 WAF, which coincides with our observations that proline content decreased at $22 \mathrm{WAF}$ in 2017 and 2019 (Figure 3). The proline levels observed in our study were approximately consistent with $\mathrm{H}_{2} \mathrm{O}_{2}$ levels in Norway maple and sycamore seeds noted by Ratajczak et al. [22]. These results can reveal the important role of proline in the removal of excessive ROS molecules A clear peak in $\mathrm{H}_{2} \mathrm{O}_{2}$ content in Norway maple seeds was synchronized between both embryonic axes and cotyledons at the 18th WAF, which corresponds with the time of desiccation tolerance acquisition [6]. Thus, the change in content of these molecules and shift to more oxidizing conditions probably functions as a signal for the acquisition of desiccation tolerance in Acer seeds [49].

Proline accumulates in plant tissues in response to the regulator of plant development, abscisic acid (ABA), which is a phytohormone that mediates signaling to start the desiccation tolerance program in developing seeds [50]. Pinfield et al. [51] and Dickie et al. [25] demonstrated that the peak endogenous levels of ABA occurred on approximately the 100th day after flowering (DAF; corresponds to 14 WAF) in sycamore seeds and on approximately the 140th DAF (20 WAF) in Norway maple seeds. These observations are partially supported by our results because proline levels in Norway maple embryonic axes reached a maximum at approximately 20 WAF (Figure 3A,C). However, maximal levels of proline occurred at approximately 17 WAF in sycamore (Figure $3 \mathrm{~A}^{\prime}-\mathrm{C}^{\prime}$ ). The time at which $\mathrm{ABA}$ and proline achieve maximum levels likely coincides with the acquisition of desiccation tolerance, which indicates the role of proline in this process $[25,52,53]$. 


\section{Conclusions}

Seed developmental processes in the Northern Hemisphere are related to desiccation tolerance, which is one of the mechanisms that protects seeds from germination in adverse conditions. As a result of climate change, mean temperature and water availability are major factors affecting seed metabolism. Understanding how these changes influence seed physiology and acquisition of desiccation tolerance may be crucial for protecting the genetic resources of forest species. These changes may be reflected in seed storability. Proline is herein indicated as a promising biochemical indicator for monitoring changes that occur during seed development. Proline content depends on changes in thermal-moisture conditions, especially in recalcitrant seeds. However, to establish proline as an indicator of high-quality seeds suitable for storage, further research should be conducted.

Supplementary Materials: The following are available online at http://www.mdpi.com/1999-4907/11/12/1362/s1, Figure S1: Correlation between proline content an week after flowering in embryonic axes of Norway maple (A); Sycamore maple (A') and cotyledons of Norway maple (B); Sycamore maple (B'), Figure S2: Anomalies in monthly average precipitation in years 2017, 2018 and 2019 in Kórnik in relation with reference period 1979-2019. Data obtained from meteorological station at experiment site in Kórnik, Poland, Figure S3: Anomalies in monthly average temperature in years 2017, 2018 and 2019 in Kórnik in relation with reference period 1979-2019. Data obtained from meteorological station at experiment site in Kórnik, Poland.

Author Contributions: Conceptualization, E.R. and J.K.-O.; investigation, J.K.-O.; writing-original draft preparation, J.K.-O. and E.R.; writing-review and editing, J.K.-O., E.R., A.M.S., M.K.W.; visualization, J.K.-O., E.R., A.M.S., M.K.W.; supervision, J.K.-O. and E.R.; funding acquisition, E.R. All authors have read and agreed to the published version of the manuscript.

Funding: This research was supported by the National Centre of Sciences (grant number 2018/31/B/NZ9/01548). Additional funding was provided by the Institute of Dendrology, Polish Academy of Sciences.

Conflicts of Interest: The authors declare no conflict of interest.

\section{References}

1. Wang, W.-Q.; Liu, S.-J.; Song, S.-Q.; Møller, I.M. Proteomics of seed development, desiccation tolerance, germination and vigor. Plant Physiol. Biochem. 2015, 86, 1-15. [CrossRef]

2. Hayat, S.; Hayat, Q.; Nasser, A.; Wani, A.S.; Pichtel, J.; Ahmad, A. Role of proline under changing environments. Plant Signal. Behav. 2012, 7, 1456-1466. [CrossRef]

3. Sharma, S.S.; Dietz, K.-J. The significance of amino acids and amino acid-derived molecules in plant responses and adaptation to heavy metal stress. J. Exp. Bot. 2006, 57, 711-726. [CrossRef]

4. Berjak, P.; Pammenter, N.W. Implications of the lack of desiccation tolerance in recalcitrant seeds. Front. Plant Sci. 2013, 4, 478. [CrossRef]

5. Pukacka, S.; Wójkiewicz, E. Carbohydrate metabolism in Norway maple and sycamore seeds in relation to desiccation tolerance. J. Plant Physiol. 2002, 159, 273-279. [CrossRef]

6. Pukacka, S.; Ratajczak, E. Ascorbate and glutathione metabolism during development and desiccation of orthodox and recalcitrant seeds of the genus Acer. Funct. Plant Biol. 2007, 34, 601-613. [CrossRef]

7. Pukacka, S.; Hoffmann, S.K.; Goslar, J.; Pukacki, P.M.; Wójkiewicz, E. Water and lipid relations in beech (Fagus sylvatica L.) seeds and its effect on storage behaviour. Biochim. Biophys. Acta Bioenerg. 2003, 1621, 48-56. [CrossRef]

8. Pukacka, S.; Ratajczak, E. Age-related biochemical changes during storage of beech (Fagus sylvatica L.) seeds. Seed Sci. Res. 2007, 17, 45-53. [CrossRef]

9. Leprince, O.; Hendry, G.A.F.; McKersie, B.D. The mechanisms of desiccation tolerance in developing seeds. Seed Sci. Res. 1993, 3, 231-246. [CrossRef]

10. Staszak, A.M.; Pawłowski, T.A. Proteomic Analysis of Embryogenesis and the Acquisition of Seed Dormancy in Norway Maple (Acer platanoides L.). Int. J. Mol. Sci. 2014, 15, 10868-10891. [CrossRef]

11. Berjak, P.; Farrant, J.M.; Pammenter, N.W. Seed Desiccation-Tolerance Mechanisms in Plant Desiccation Tolerance, 1st ed.; Jenks, M.A., Wood, A.J., Eds.; Blackwell Publishing: Ames, IA, USA, 2007; pp. 151-192, ISBN 978-0-8138-1263-2. 
12. Leprince, O.; Buitink, J.; Hoekstra, F.A. Axes and cotyledons of recalcitrant seeds of Castanea sativa Mill. exhibit contrasting responses of respiration to drying in relation to desiccation sensitivity. J. Exp. Bot. 1999, 50, 1515-1524. [CrossRef]

13. Sharma, P.; Jha, A.B.; Dubey, R.S.; Pessarakli, M. Reactive Oxygen Species, Oxidative Damage, and Antioxidative Defense Mechanism in Plants under Stressful Conditions. J. Bot. 2012, 2012,1-26. [CrossRef]

14. Ali, Q.; Ashraf, M.; Shahbaz, M.; Humera, H. Ameliorating effect of foliar applied proline on nutrient uptake in water stressed maize (Zea mays L.) plants. Pak. J. Bot. 2008, 40, 211-219.

15. Liang, X.; Zhang, L.; Natarajan, S.K.; Becker, D.F. Proline Mechanisms of Stress Survival. Antioxid. Redox Signal. 2013, 19, 998-1011. [CrossRef]

16. Shevyakova, N.I.; Bakulina, E.A.; Kuznetsov, V.V. Proline antioxidant role in the common ice plant subjected to salinity and paraquat treatment inducing oxidative stress. Russ. J. Plant Physiol. 2009, 56, 663-669. [CrossRef]

17. Kaur, G.; Kumar, S.; Thakur, P.; Malik, J.A.; Bhandhari, K.; Sharma, K.D.; Nayyar, H. Involvement of proline in response of chickpea (Cicer arietinum L.) to chilling stress at reproductive stage. Sci. Hortic. 2011, 128, 174-181. [CrossRef]

18. Kumar, V.; Shriram, V.; Hossain, M.; Kishor, P. Engineering Proline Metabolism for Enhanced Plant Salt Stress Tolerance. Manag. Salt Toler. Plants 2015, 353-372.

19. Schertl, P.; Cabassa, C.; Saadallah, K.; Bordenave, M.; Savouré, A.; Braun, H.-P. Biochemical characterization of proline dehydrogenase in Arabidopsis mitochondria. FEBS J. 2014, 281, 2794-2804. [CrossRef]

20. Margutti, M.P.; Reyna, M.; Meringer, M.V.; Racagni, G.E.; Villasuso, A.L. Lipid signalling mediated by PLD/PA modulates proline and $\mathrm{H}_{2} \mathrm{O}_{2}$ levels in barley seedlings exposed to short- and long-term chilling stress. Plant Physiol. Biochem. 2017, 113, 149-160. [CrossRef]

21. Jacoby, R.P.; Taylor, N.L.; Millar, A.H. The role of mitochondrial respiration in salinity tolerance. Trends Plant Sci. 2011, 16, 614-623. [CrossRef]

22. Ratajczak, E.; Dietz, K.-J.; Kalemba, E.M. The Occurrence of Peroxiredoxins and Changes in Redox State in Acer platanoides and Acer pseudoplatanus During Seed Development. J. Plant Growth Regul. 2018, 38, 298-314. [CrossRef]

23. Belmonte, M.F.; Donald, G.; Reid, D.M.; Yeung, E.C.; Stasolla, C. Alterations of the glutathione redox state improve apical meristem structure and somatic embryo quality in white spruce (Picea glauca). J. Exp. Bot. 2005, 56, 2355-2364. [CrossRef]

24. Tobias, M.N.; Pammenter, N.W. Dehydration Kinetics of Embryonic Axes from Desiccation-sensitive Seeds: An Assessment of Descriptive Models. J. Integr. Plant Biol. 2009, 51, 1002-1007. [CrossRef]

25. Dickie, J.B.; May, K.; Morris, S.V.A.; Titley, S.E. The effects of desiccation on seed survival in Acer platanoides L. and Acer pseudoplatanus L. Seed Sci. Res. 1991, 1, 149-162. [CrossRef]

26. Dietz, K.-J.; Hell, R. Thiol switches in redox regulation of chloroplasts: Balancing redox state, metabolism and oxidative stress. Biol. Chem. 2015, 396, 483-494. [CrossRef]

27. De Gara, L.; De Pinto, M.C.; Moliterni, V.M.C.; D’Egidio, M.G. Redox regulation and storage processes during maturation in kernels of Triticum durum. J. Exp. Bot. 2003, 54, 249-258. [CrossRef]

28. Fu, Y.-B.; Ahmed, Z.; Diederichsen, A. Towards a better monitoring of seed ageing underex situseed conservation. Conserv. Physiol. 2015, 3, cov026. [CrossRef]

29. Bogdziewicz, M.; Kelly, D.; Thomas, P.A.; Lageard, J.G.A.; Hacket-Pain, A. Climate warming disrupts mast seeding and its fitness benefits in European beech. Nat. Plants 2020, 6, 88-94. [CrossRef]

30. Rafferty, N.E.; Nabity, P.D. A global test for phylogenetic signal in shifts in flowering time under climate change. J. Ecol. 2016, 105, 627-633. [CrossRef]

31. Dobrowolska, D. Vitality of European Beech (Fagus sylvaticaL.) at the Limit of Its Natural Range in Poland. Pol. J. Ecol. 2015, 63, 260-272. [CrossRef]

32. Bogdziewicz, M.; Fernández-Martínez, M.; Bonal, R.; Belmonte, J.; Espelta, J.M. The Moran Effect and Environmental Vetoes: Phenological Synchrony and Drought Drive Seed Production in a Mediterranean Oak. Proc. R. Soc. B 2017, 284, 20171784. [CrossRef]

33. Noctor, G.; Reichheld, J.-P.; Foyer, C.H. ROS-related redox regulation and signaling in plants. Semin. Cell Dev. Biol. 2018, 80, 3-12. [CrossRef]

34. Wang, W.-Q.; Cheng, H.-Y.; Møller, I.M.; Song, S.-Q. The role of recovery of mitochondrial structure and function in desiccation tolerance of pea seeds. Physiol. Plant. 2011, 144, 20-34. [CrossRef] 
35. Probert, R.; Adams, J.; Coneybeer, J.; Crawford, A.; Hay, F. Seed quality for conservation is critically affected by pre-storage factors. Aust. J. Bot. 2007, 55, 326-335. [CrossRef]

36. Carillo, P.; Gibon, Y. Protocol: Extraction and Determination of Proline. Available online: http://prometheuswiki.publish.csiro.au/tikiindex.php?page=PROTOCOL\%3A+Extraction+and+ determination+of+proline (accessed on 11 August 2020).

37. Core Team. R: A Language and Environment for Statistical Computing; R Foundation for Statistical Computing: Vienna, Austria; Available online: https://www.R-project.org/ (accessed on 11 August 2018).

38. Makowski, D.; Ben-Shachar, M.S.; Patil, I.; Lüdecke, D. Methods and Algorithms for Correlation Analysis in R. J. Open Source Softw. 2020, 5, 2306. [CrossRef]

39. Kalemba, E.M.; Pukacka, S. Association of Protective Proteins with Dehydration and Desiccation of Orthodox and Recalcitrant Category Seeds of Three Acer Genus Species. J. Plant Growth Regul. 2011, 31, 351-362. [CrossRef]

40. Pukacka, S.; Pukacki, P.M. Changes in soluble sugars in relation to desiccation tolerance and effects of dehydration on freezing characteristics of Acer platanoides and Acer pseudoplatanus seeds. Acta Physiol. Plant. 1997, 19, 147-154. [CrossRef]

41. Walters, C. Orthodoxy, recalcitrance and in-between: Describing variation in seed storage characteristics using threshold responses to water loss. Planta 2015, 242, 397-406. [CrossRef]

42. Berjak, P.; Pammenter, N.W. Recalcitrance is not an all-or-nothing situation. Seed Sci. Res. 1994, 4, 263-264. [CrossRef]

43. Foyer, C.H.; Noctor, G. Ascorbate and Glutathione: The Heart of the Redox Hub. Plant Physiol. 2011, 155, 2-18. [CrossRef]

44. Kaur, G.; Asthir, B. Proline: A key player in plant abiotic stress tolerance. Biol. Plant. 2015, 59, 609-619. [CrossRef]

45. Aggarwal, M.; Sharma, S.; Kaur, N.; Pathania, D.; Bhandhari, K.; Kaushal, N.; Kaur, R.; Singh, K.; Srivastava, A.; Nayyar, H. Exogenous Proline Application Reduces Phytotoxic Effects of Selenium by Minimising Oxidative stress and Improves Growth in Bean (Phaseolus vulgaris L.) Seedlings. Biol. Trace Elem. Res. 2011, 140, 354-367. [CrossRef]

46. Hoque, A.; Banu, M.N.A.; Okuma, E.; Amako, K.; Nakamura, Y.; Shimoishi, Y.; Murata, Y. Exogenous proline and glycinebetaine increase $\mathrm{NaCl}$-induced ascorbate-glutathione cycle enzyme activities, and proline improves salt tolerance more than glycinebetaine in tobacco Bright Yellow-2 suspension-cultured cells. J. Plant Physiol. 2007, 164, 1457-1468. [CrossRef]

47. Oliver, M.J.; Farrant, J.M.; Hilhorst, H.W.M.; Mundree, S.G.; Williams, B.; Bewley, J.D. Desiccation Tolerance: Avoiding Cellular Damage During Drying and Rehydration. Annu. Rev. Plant Biol. 2020, 71, 435-460. [CrossRef]

48. Cunningham, D.F.; O'Connor, B. Proline specific peptidases. Biochim. Biophys. Acta Protein Struct. Mol. Enzym. 1997, 1343, 160-186. [CrossRef]

49. Baxter, A.; Mittler, R.; Suzuki, N. ROS as key players in plant stress signalling. J. Exp. Bot. 2014, 65, 1229-1240. [CrossRef]

50. Hasanuzzaman, M.; Nahar, K.; Anee, T.I.; Fujita, M. Glutathione in plants: Biosynthesis and physiological role in environmental stress tolerance. Physiol. Mol. Biol. Plants 2017, 23, 249-268. [CrossRef]

51. Pinfield, N.J.; Stutchbury, P.A.; Bazaid, S.A.; Gwarazimba, V.E.E. Abscisic acid and the regulation of embryo dormancy in the genus Acer. Tree Physiol. 1990, 6, 79-85. [CrossRef]

52. Schroeder, D.F.; Fernando, V.C.D. Role of ABA in Arabidopsis Salt, Drought, and Desiccation Tolerance. In Abiotic and Biotic Stress in Plants—Recent Advances and Future Perspectives; Shanker, A.K., Shanker, C., Eds.; InTech: London, UK, 2016; ISBN 978-953-51-2250-0.

53. Ratajczak, E.; Małecka, A.; Ciereszko, I.; Staszak, A.M. Mitochondria Are Important Determinants of the Aging of Seeds. Int. J. Mol. Sci. 2019, 20, 1568. [CrossRef]

Publisher's Note: MDPI stays neutral with regard to jurisdictional claims in published maps and institutional affiliations. 